\title{
A new sprout inhibitor of potato tuber based on carvone/ $\beta$-cyclodextrin inclusion compound
}

\author{
M. Costa E Silva · C. I. C. Galhano · \\ A. M. G. Moreira Da Silva
}

Received: 15 May 2006/ Accepted: 20 October 2006/ Published online: 18 January 2007

(C) Springer Science+Business Media B.V. 2007

\begin{abstract}
A monoterpene, D-carvone or (4S)-(+)carvone, present in the essential oil of caraway seeds (Carum carvi L.), acts as a sprouting inhibitor agent for potato tubers in storage. The aim of the present study was to investigate the possibility of using carvone/ $\beta$-cyclodextrin inclusion compound as a sprout inhibitor agent for potato tubers. A Raman study of the interactions between $\beta$-cyclodextrin $(\beta$-CD) and included carvone molecule in solid state is also reported; the results confirm the synthesis of inclusion compound at pilot scale level.
\end{abstract}

Keywords Carvone $\cdot \beta$-cyclodextrin $\cdot$ Inclusion compound $\cdot$ Sprout inhibitor $\cdot$ Potato tuber

\section{Introduction}

Potato is the fourth most important food crop in the world mainly due to its starch content and high quality

M. Costa E Silva - A. M. G. Moreira Da Silva ( $\square)$

Department of Food Science and Technology, ESAC-IPC,

Bencanta, Coimbra 3040-316, Portugal

e-mail: aidams@esac.pt

C. I. C. Galhano

Department of Pure and Environmental Sciences, ESAC-

IPC, Bencanta, Coimbra 3040-316, Portugal

C. I. C. Galhano

CERNAS Research Unit, Bencanta, Coimbra 3030-316,

Portugal

A. M. G. Moreira Da Silva

Physical-Chemistry Research Unit, Department of

Chemistry, University of Coimbra, Coimbra 3030-535,

Portugal protein, substantial amounts of essential vitamins, minerals, and very low fat content. Sprouting is a common problem during winter storage of potato tubers. Chlorpropham (CIPC), a carbamate, is a traditional chemical often applied to prevent this problem and increase the storage period. Despite its relatively low toxicity, there is a demand for alternative non-chemical sprout suppressants, either legislative or marketing reasons.

The use of volatile plant compounds in post-harvest potato storage is an ancient concept [1, 2].(4S)-(+)Carvone, present in the essential oil of caraway seeds (Carum carvi L.), is being used as a sprouting inhibitor agent for potatoes and seed potatoes in storage [2]. However, this compound is extremely volatile and therefore unstable. Inclusion of carvone into $\beta$-cyclodextrin reduces volatility and improves stability [2]. In this work, the effect of carvone/ $\beta$-cyclodextrin inclusion compound was studied. A Raman spectroscopic study of the interactions between $\beta$-CD and carvone in solid state is also reported.

\section{Methodology}

$\beta$-CD (KLEPTOSE) was kindly offered by Roquette, France, and the $S$-carvone (2-methyl-5-(1-methylethenyl)-2-cyclohexen-1-one or (4S)-(+)-Carvone)-Scheme I-was purchased from Aldrich or extracted from Carum carvi L. (caraway) seeds by supercritical method and/or hydrodistillation (2.2-2.9 g/100 g of dried seeds) [3, 4].

Inclusion compound preparation (pilot scale)

$\beta$-CD (273 g) was dissolved in $15 \mathrm{~L}$ of distilled water to form a clear solution, at $353 \mathrm{~K}$ in a B. Braun Biotech 


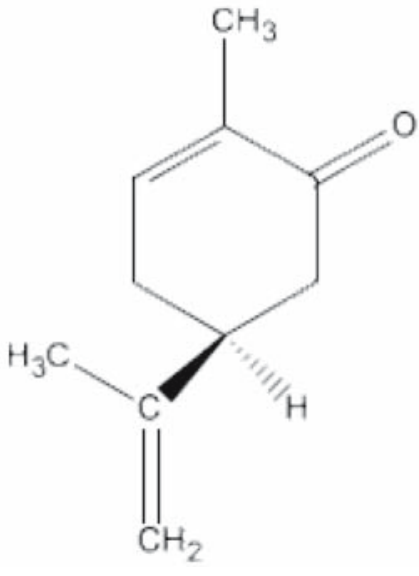

(4S)- (+) -Carvone

Scheme 1

Biostat ED DCU2 Fermentor. The $S$-carvone $(37.7 \mathrm{~mL})$ was added drop-wise to $\beta$-CD solution. The mixture was vigorously stirred over night with a magnetic stirrer at room temperature. White precipitate was filtered and dried for 1-2 days over ambient atmosphere (ca. $90 \%(\mathrm{~m} / \mathrm{m})$ yield).

The $\beta$-CD carvone inclusion compound was characterized by ${ }^{1} \mathrm{H}-\mathrm{NMR}$ and Raman spectroscopic studies $[5,6]$.

Potato tuber storage experiments

\section{4-2005 Preliminary experiment}

This experiment was conducted for 6 weeks using the potato cultivar "Monalisa". Five wood containers of $70 \times 50 \mathrm{~cm}^{2}$ each were placed in a cool storage room at $283 \mathrm{~K}$, and $80-90 \%$ relative humidity $(\mathrm{RH})$, with $15 \mathrm{~cm}$ of distance between them. Seventy potato tubers (ca. $140 \mathrm{~g} /$ potato) making $10 \mathrm{~kg}$ of total weight were layered in each container.

The potato tubers of each of the four containers were submitted to different treatments: 1-homogenous distribution of $6 \mathrm{~mL}$ de $S$-(+)-carvone by regular sprinkling, once a week; 2-homogenous distribution of $25 \mathrm{~g}$ of the inclusion compound carvone/ $\beta$-cyclodextrin, once a week; 3-homogenous distribution of $10 \mathrm{~g}$ of the common sprout inhibitor, chlorpropham (CIPC); 4-homogenous distribution of $337 \mathrm{~g}$ of caraway seeds. The fifth container was left without any treatment, as a control. Measurements of the number and the length of sprouts in each treatment and in control were made weekly. The results were expressed as sprouting percentage in relation to the total number of potato tubers in each treatment (70).
2005-2006 Experiment

This experiment was conducted for 14 weeks using the potato cultivar "Agria". Five bigbags, each with $77 \mathrm{~kg}$ of potato tubers, were placed in a cool storage room at $283 \mathrm{~K}$, and $80-90 \% \mathrm{RH}$. The potato tubers of four of the "bigbags" were submitted to different treatments: 1 -homogenous distribution of $200.2 \mathrm{~g}$ of the inclusion compound carvone/ $\beta$-cyclodextrin, every 15 days; 2 -homogenous distribution of $77 \mathrm{~g}$ of the common sprout inhibitor, CIPC, twice during the experiment; 3 -homogenous distribution of $2595 \mathrm{~g}$ of caraway seeds, once during the experiment; 4-homogenous distribution of $46.2 \mathrm{~mL}$ of $S$-(+)-carvone by regular sprinkling; every 15 days. Measurements of the number and the length of sprouts in each treatment and in control were made every 15 days on 10 randomly chosen potato tubers, and the results expressed as explained above.

Raman spectroscopic studies

The sample was inserted in a Kimax capillary tube and room temperature $(T=298 \mathrm{~K})$ raman spectra were recorded on a T64000 Jobin Yvon spectrometer, working in the subtractive configuration (i.e., double premonochromator stage in subtractive configuration, plus third stage spectrograph), with relevant slit widths set to $320 \mu \mathrm{m}$ and the intermediate slit between premonochromator and spectrograph wide open $(14 \mathrm{~mm})$. The detecting device was a CCD detector. An $\mathrm{Ar}^{+}$ laser (Innova 300-05 model with power track, from Coherent) at $514 \mathrm{~nm}$ provided ca. $100 \mathrm{~mW}$ at the sample position.

\section{Results and discussion}

Studies of sprouting inhibition of potato tuber

According to the results obtained in the preliminary experiment (Fig. 1), the carvone treatment had the most efficient sprout inhibitory effect as it was already found in other studies [1, 2]. However, the inclusion compound treatment also demonstrated a potential inhibitory effect compared with the control.

In the second experiment, the potato tubers treated with carvone (Treatment 4 ) rotted due to the sprinkling and the accumulation of humidity. The results obtained in the other treatments showed that the inclusion compound treatment had the most efficient sprout inhibitory effect followed by CIPC, and caraway seeds (Fig. 2). These studies deserve further investigation. 
Fig. 1 Sprouting (\%) reported in each treatment and in the control over the preliminary experiment period (May-June of 2004) $(\mathrm{cm})$ of sprouted tubers reported in each treatment and in the control over the second experiment period (December 2005-1 March 2006)
Fig. 2 Sprout average length
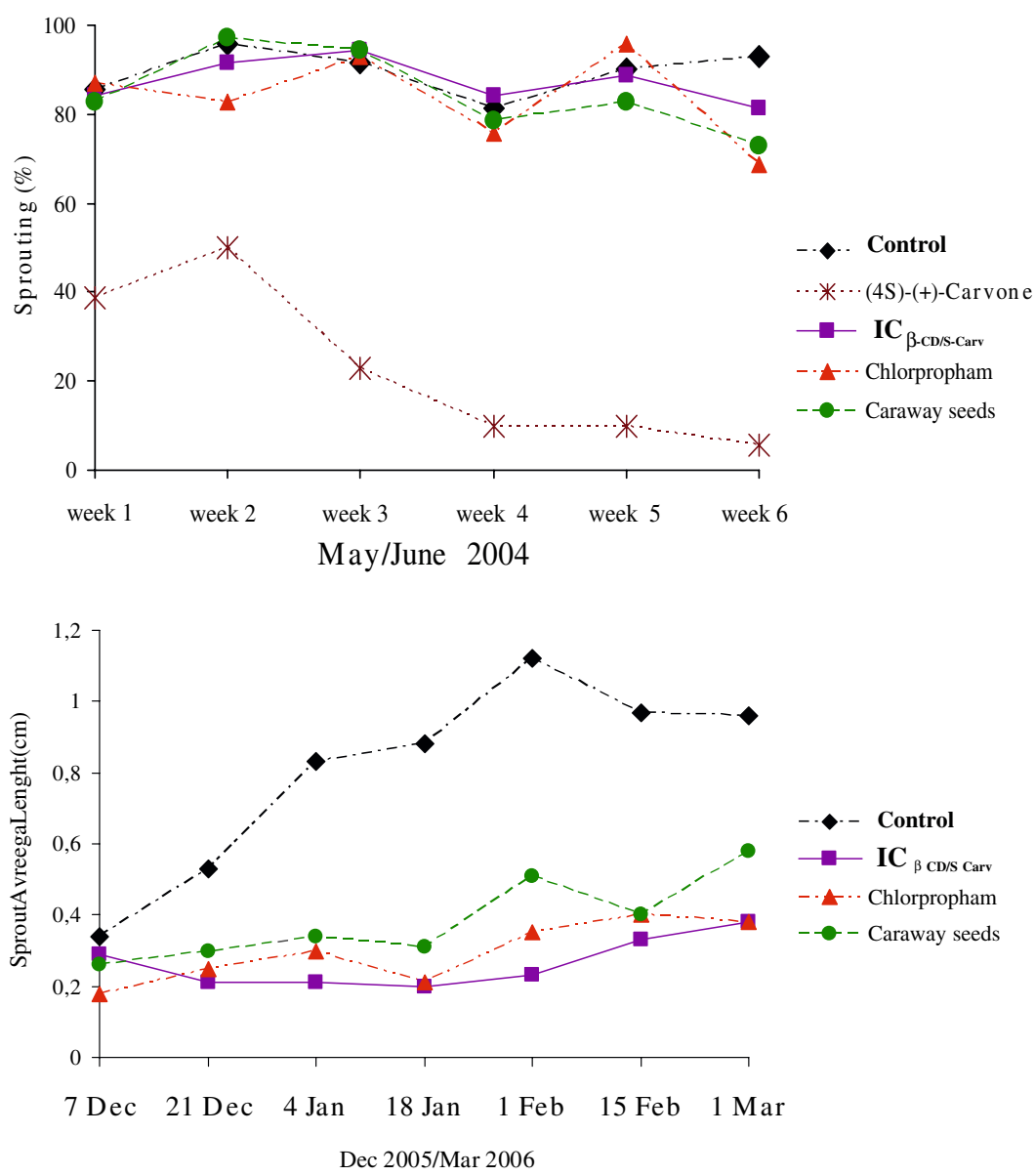

Inclusion compound raman spectroscopic characterization

The stoichiometry and the apparent inclusion constants were determined in previous work by "Job plots" and linear regression methods, respectively. The apparent association constant at room temperature for the 1:1 inclusion of $S$-(+)-carvone in $\beta$-cyclodextrin is $1330 \mathrm{~mol} . \mathrm{dm}^{-3}(c v=10 \%)$, at $T=286 \mathrm{~K}[5,6]$.

Figure 3 presents the Raman spectra of Inclusion Compound, IC $\beta$-CD/s-Carv (a) $\beta$-cyclodextrin, $\beta$-CD (b) $S$-Carvone (c) in the region $1500-1750 \mathrm{~cm}^{-1}$. The more relevant spectral features presented in these spectra are $v \mathrm{C}=\mathrm{C}\left(1624-1647 \mathrm{~cm}^{-1}\right)$ and $v \mathrm{C}=\mathrm{O}$ $\left(1668-1706 \mathrm{~cm}^{-1}\right)$ [7].

Table 1 summarizes the most important spectral results which occur in a frequency region relatively free from other $v \mathrm{C}-\mathrm{H}$ bands. It can be seen that positive significant frequency shifts of $v \mathrm{C}=\mathrm{O} \quad(1670.3-$ $1677.3 \mathrm{~cm}^{-1}$ ).

The spectral comparisons emerging both from Raman spectra show in Figure 4 and Table 1 leads to confirmation that inclusion occurs, using $\mathrm{C}=\mathrm{O}$ bond as vibrational probe. The observed shift in spectral bands is consistent with presence of inclusion compounds, but does not prove that solid material consist only inclusion compounds. As a hydrogen bond acceptor, the $\mathrm{C}=\mathrm{O}$ bond of carvone can act as the anchoring group for the guest in the inclusion process. The observed no significant change in the $v \mathrm{C}=\mathrm{C}$ band implies that this vibration is not affect by inclusion. In fact, the results of molecular mechanics calculations on model systems help in the interpretation of these experimental results. The $S$-Carv inside $\beta$-CD have the $\mathrm{C}=\mathrm{O}$ group of carvone involved in a hydrogen bonding interaction with one hydroxyl group of $\beta$-CD. In the most stable inclusion compound model, the ( $S$-carvone) $\mathrm{C}=\mathrm{O} \cdots \mathrm{H}-\mathrm{O}(\beta-\mathrm{CD})$ interaction is directed to one primary hydroxyl group of $\beta$-CD, $\mathrm{C}=\mathrm{O} \cdots \mathrm{HOC}(6)[6]$.

\section{Conclusion}

The results herein reported for carvone and inclusion compound carvone/ $\beta$-cyclodextrin indicates that these 
Fig. 3 Raman spectra of Inclusion Compound $\mathrm{IC}_{\mathrm{S}}$ Carv/ $-\beta \mathrm{CD}$ (a) $\beta$-cyclodextrin, $\beta$-CD; (b) $S$-Carvone, $S$-Carv; (c). The intensity change and shift of $1600-1700 \mathrm{~cm}^{-1}$ bands shows that inclusion occurs

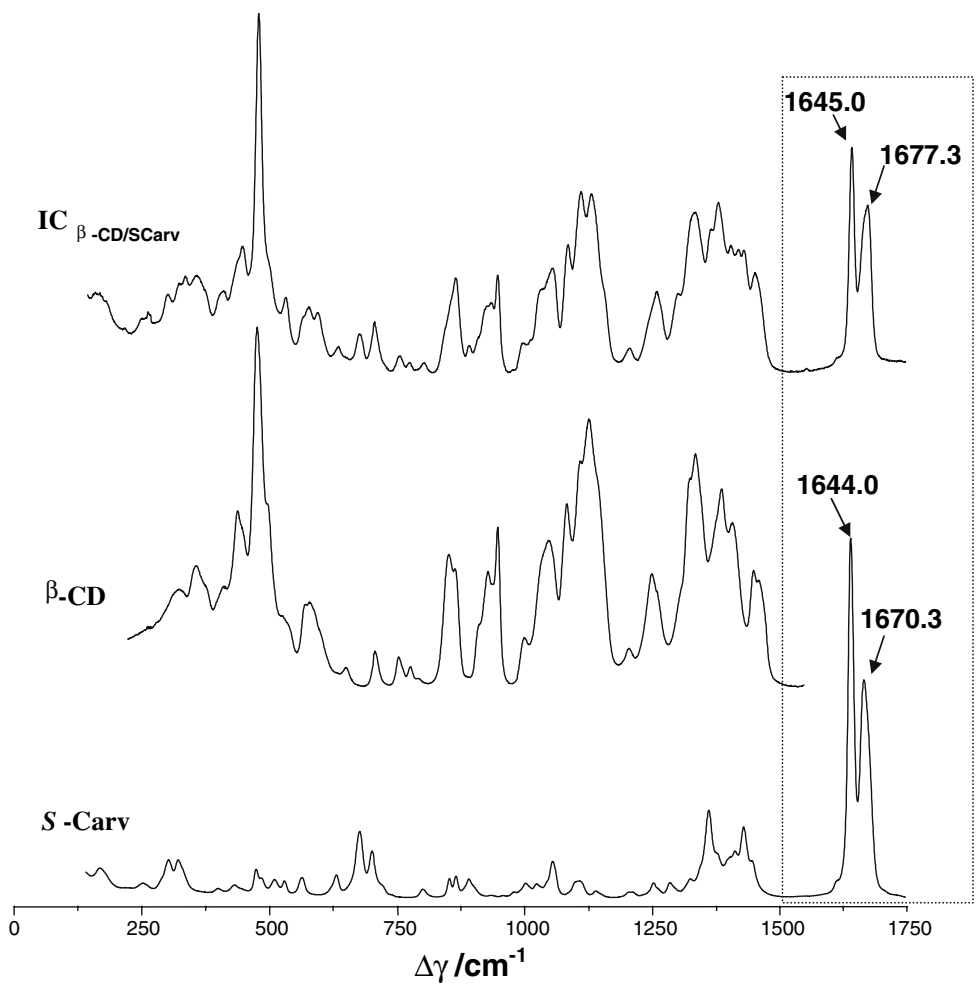

Table 1 Raman frequencies $\left(\mathrm{cm}^{-1}\right)$

\begin{tabular}{lllll}
\hline System & $v \mathrm{C}=\mathrm{O}$ & $\Delta v \mathrm{C}=\mathrm{O}$ & $v \mathrm{C}=\mathrm{C}$ & $\Delta v \mathrm{C}=\mathrm{C}$ \\
\hline$\beta$-CD & $-(*)$ & & $-\left(^{*}\right)$ & \\
Carv & 1670.3 & - & 1644 & \\
$\mathrm{IC}_{\text {Carv } / \beta-\mathrm{CD}}$ & 1677.3 & +7 & 1645 & +1
\end{tabular}

(*) $\beta$-CD window spectral region are $\nu \mathrm{C}=\mathrm{O}\left(1668-1706 \mathrm{~cm}^{-1}\right)$; $\nu \mathrm{C}=\mathrm{C}\left(1624-1647 \mathrm{~cm}^{-1}\right)$

systems satisfy the basic requirements for use in sprout suppression in Solanum tuberosum L. tubers.

In addition, the inclusion compound carvone/ $\beta$ cyclodextrin treatment can be considered as a potential new sprout inhibitor. Further studies should be done in order to clarify the economic advantages of the use of inclusion compound carvone/ $\beta$-cyclodextrin as potato tuber sprout suppressant.

Acknowledgments $\beta$-cyclodextrin was kindly offered by Roquette. Thanks to M. P. M. Marques for acquisition of Raman spectra. This work was supported by the Portuguese Ministry of Agriculture under Programa AGRO (PO_AGRO 691), Medida 8-Desenvolvimento, Experimentação e Demonstração, Acção 8.1-Desenvolvimento Experimental e Demonstração (DE\&D).

\section{References}

1. Vaughn, S., Spencer, G.F.: Volatile monoterpenes inhibit potato tuber sprout. Amer. Potato J. 68, 821-831 (1991)

2. Oosterhaven, J.: Different aspects of S-Carvone, a natural potato sprout inhibitor. WAU dissertation $\mathrm{n}^{\circ}$ 1988, Ph.D. Thesis, Wageningen University, 1995

3. Baysal, T., Starmans, D.A.J.: Supercritical carbon dioxide extraction of carvone and limonene from caraway seed. J. Supercrit. Fluids 14, 225 (1999)

4. Bouwmeester, H., Davies, J., Toxopeus, H.: Enantiomeric composition of carvone, limonene, and carveols in seeds of dill and biennial caraway varieties. J. Agric. Food Chem. 43(12), 3057-3064 (1995)

5. Moreira da Silva, A., Empis, J., Teixeira-Dias, J.: Preferencial inclusion in $\beta$-cyclodextrin of one of the enantiomers of carvone: a ${ }^{1} \mathrm{H}-\mathrm{NMR}$ study in aqueous solution. J. Inclusion Phenom. 33, 81-97 (1999)

6. Moreira da Silva, A., Empis, J., Teixeira-Dias, J.: Inclusion of carvone enantiomers in $\beta$-cyclodextrin: thermal behaviour and H/D, D/H exchanges. J. Carb. Res. 337, 2501-2505 (2002)

7. Moreira da Silva, A., Amado, A.M., Ribeiro Claro, P.J., Empis, J., Teixeira Dias, J.J.C.: $\beta$-Cyclodextrin complexes of benzaldehyde, vanillin and cinnamaldehyde: a Raman spectroscopic study. J. Carb. Chem. 14(4\&5), 677-684 (1995) 